\title{
Danos causados por diferentes potenciais de inóculo de Aspergillus ochraceus no vigor de sementes de soja
}

\section{Damage caused by different inoculum levels of Aspergillus ochraceus on the vigour of soybean seeds}

\author{
Fernando da Silva Rocha ${ }^{1 *}$; Hugo Cesar Rodrigues Moreira Catão'; \\ Antônio de Amorim Brandão ${ }^{3}$; Luiz Antônio Augusto Gomes ${ }^{4}$
}

\begin{abstract}
Resumo
A incidência e a severidade de Aspergillus ochraceus pode reduzir a qualidade fisiológica das sementes. Neste trabalho, objetivou-se estudar a qualidade fisiológica de sementes de soja naturalmente infectadas com A. ochraceus. Sementes de soja cv. Conquista com diferentes níveis de inóculo de A. ochraceus foram obtidas por meio da técnica de restrição hídrica e separadas em três níveis (N0, N1 e N2) de acordo com a área superfícial coberta com estruturas fúngicas. Para compor as testemunhas foram retiradas do tratamento N0 duas amostras de 200 sementes de soja, sendo a primeira tratada com os fungicidas carboxin + thiram e a segunda amostra submetida à desinfestação superficial por imersão em solução de hipoclorito de sódio. A seguir, avaliou-se o vigor das sementes por meio do teste de emergência em bandejas e pelo teste de tetrazólio. As avaliações do comprimento de plântulas, massa fresca e massa seca da parte aérea e da raiz foram realizadas aos 21 dias após a semeadura. Observou-se redução do índice de velocidade de emergência e da emergência de plântulas com níveis de até $50 \%$ de inóculo em comparação ao tratamento com fungicida. O comprimento das plântulas (44\%), a massa fresca da parte aérea e da raiz (82\%), a massa seca da parte aérea (81\%) e a massa seca da raiz (76\%) também foram reduzidos. Sementes de soja com incidência acima de $50 \%$ de $A$. ochraceus apresentaram perda total do vigor e deterioração dos tecidos.
\end{abstract}

Palavras-chave: Deterioração de semente, fungos de armazenamento, Glycine max

\begin{abstract}
The incidence and severity of Aspergillus ochraceus can reduce seed quality. In this study, we aimed to study the physiological quality of soybean seeds naturally infected with $A$. ochraceus. Seeds of soybean cv. Conquest with different levels of inoculum of $A$. ochraceus were obtained by the technique of water and separated into three classes (N0, N1 and N2) according to the constraint surface area covered with fungal structures. The control samples were taken from the N0 treatment, two samples of 200 soybean seeds, the first being treated with fungicides carboxin + thiram and the second sample subjected to surface disinfestation by immersion in a solution of sodium hypochlorite. Next, we assessed the vigour of seeds through the emergency test in trays and the tetrazolium test. The length, seedling fresh and dry weight of shoot and root were evaluated at 21 days after sowing. There was a reduction in the rate
\end{abstract}

${ }^{1}$ Eng $^{\mathrm{o}}$ Agr $^{\mathrm{o}}$, Prof. Dr. Fitopatologia, Universidade Federal de Minas Gerais, UFMG/ICA, Montes Claros, MG. E-mail: rochafsplant@yahoo.com.br

${ }^{2}$ Eng $^{\circ}$ Agr $^{\circ}$, Dr., Dept ${ }^{\circ}$ de Agricultura/Fitotecnia, Universidade Federal de Lavras, UFLA, Lavras, MG. E-mail: hugocatao@ yahoo.com.br

${ }^{3}$ Eng $^{\circ}$ Agr $^{\circ}$, M.e, Discente do Curso de Doutorado, Universidade Federal Rural Rio de Janeiro, UFRRJ, Seropédica, RJ. E-mail: toniagrick@yahoo.com.br

${ }^{4}$ Eng $^{\text {o }}$ Agr ${ }^{\circ}$, Prof. Dr., Dept ${ }^{\mathrm{o}}$ de Agricultura, UFLA, Lavras, MG. E-mail: laagomes@dag.ufla.br

* Autor para correspondência 
of speed of emergence and seedling emergence in the seeds with levels of up to $50 \%$ of inoculum compared to treatment with fungicide. The length of the seedlings (44\%), fresh weight of shoot and root $(82 \%)$, dry weight of shoots $(81 \%)$ and root dry mass $(76 \%)$ were also reduced . Soybean seeds with incidence above $50 \%$ of $A$. ochraceus showed total loss of vigor and decay of tissues.

Key words: Seed deterioration, storage fungi, Glycine max

\section{Introdução}

A cultura da soja (Glycine max L.) apresenta grande importância socioeconômica para o Brasil, sendo considerado um dos principais produtos de exportação do país. Diante disto, torna-se primordial a utilização de sementes que apresentem alta qualidade, que se caracteriza como materiais que apresentem qualidade genética, física, fisiológica e sanitária (BRACCINI et al., 2003), tornando assim a semente um fator preponderante para o estabelecimento das lavouras, o que possibilita maior produtividade e rendimento por aérea (CATÃO et al., 2013).

A qualidade da semente obtida no campo deve ser mantida no armazenamento até a próxima semeadura (GALLI; PANIZZI; VIEIRA, 2007). Nesse sentido, o armazenamento constitui uma etapa em que se procura reduzir a velocidade e a intensidade do processo de deterioração, principalmente nas sementes de soja, que são colhidas e armazenadas por um longo período (KROHN; MALAVASI, 2004). A armazenabilidade das sementes é influenciada pela qualidade inicial dos lotes, bem como pelas condições de armazenamento (CATÃO et al., 2010).

As condições abióticas do ambiente favoráveis à conservação da qualidade da semente são a baixa temperatura e a baixa umidade relativa do ar (GALLI; PANIZZI; VIEIRA, 2007). No entanto, as mesmas condições de armazenamento que permitem a manutenção da viabilidade das sementes, podem também favorecer a sobrevivência de muitos patógenos. Os patógenos que podem comprometer a qualidade das sementes podem ser divididos em dois grupos: os de campo e os de armazenamento (MILLER, 1995; TANAKA, 2001). Dentre os fungos de armazenamento, os mais frequentes são Aspergillus spp. e Penicillium spp. (TUITE et al., 1985; PEREIRA et al., 1994; LUZ, 1995; PINTO, 1998). Os fungos de armazenamento estão presentes nas sementes recém-colhidas, geralmente em porcentagens baixas e são capazes de sobreviver em ambiente com baixa umidade, proliferando em sucessão aos fungos de campo causando a deterioração das sementes além de produzirem micotoxinas que causam intoxicações em humanos e animais (MILLER, 1995; CARVALHO; NAKAGAWA, 2000). Uma das mais importantes micotoxinas é a ocratoxina $\mathrm{A}$, produzida por vários fungos contaminantes, dentre deles destaca-se o fungo Aspergillus ochraceus (BATISTA et al.; 2003; SUÁREZ-QUIROZ et al., 2004; ALMEIDA et al., 2008).

Lotes contaminados nem sempre estão disponíveis prontamente ou contém o tipo de patógeno e os níveis desejados de infecção, dificultando os estudos no âmbito da patologia de sementes (FARIAS et al., 2010). Contudo, com a modificação do potencial osmótico do substrato, técnica esta denominada restrição hídrica (COUTINHO et al., 2001; MACHADO; LANGERAK, 2002; MACHADO et al., 2008) é possível promover diferentes níveis de infecção por fungos nas sementes, além de inibir a germinação das mesmas (MACHADO et al., 2004, ARAUJO et al., 2006). Desta forma, objetivou-se, neste trabalho verificar os danos fisiológicos em sementes de soja promovidos por diferentes potenciais de inóculo de Aspergillus ochraceus.

\section{Material e Métodos}

O experimento foi conduzido no Laboratório de Fitopatologia da Universidade Federal de Minas Gerais - Minas Gerais (MG), onde foram utilizadas 
sementes de soja da cultivar Conquista da safra 2010/2011, armazenadas em sacarias à temperatura ambiente. Inicialmente foi realizado um préteste para determinar a sanidade das sementes. Este pré-teste de sanidade foi realizado conforme Brasil (2009a) onde as sementes foram imersas em solução de hipoclorito de sódio a $1 \%$ por 3 minutos e distribuídas assepticamente sobre meio BDA contendo $150 \mathrm{~g}$ de cloreto de sódio por litro de meio de cultivo (meio ágar salino). Posteriormente, as placas, com sementes foram colocadas em câmara de incubação, sob luz fluorescente branca, fotoperíodo de 12 horas, a temperatura de $20^{\circ} \mathrm{C}$ por período de sete dias.

Para obter os diferentes níveis de infecção de A. ochraceus foram distribuídas 6000 sementes de maneira uniforme em bandejas de plástico contendo 100 sementes/bandeja. As bandejas receberam três folhas de papel para germinação previamente esterilizadas e umedecidas em meio ágar-água contendo manitol no potencial osmótico de $-1,0 \mathrm{Mpa}$ (MACHADO et al., 2003). Para calcular a quantidade de manitol usado na preparação do meio osmoticamente modificado, utilizou-se o programa SPMM (MICHEL; RADCLIFFE, 1995). Em seguida, as sementes foram mantidas em câmara de incubação do tipo BOD à temperatura de $20 \pm 2^{\circ} \mathrm{C}$ com fotoperíodo de 12 horas, durante sete dias. Após este período, as sementes foram agrupadas de acordo com o percentual da área superfícial do tegumento coberta somente com estruturas de A. ochraceus em três níveis de inóculo: N0-sementes sem inóculo, N1-sementes com até $50 \%$ da superfície coberta pelo inóculo e N2-sementes apresentando acima de $50 \%$ da superfície coberta pelo inóculo (Figura 1). A identificação de A. ochraceus foi baseada em suas características morfológicas (RAPER; FENNEL, 1965; CHRISTENSEN, 1982; KLICH; PITT 2002) em exame sob microscópio estereoscópico e, quando necessário, foram feitas lâminas com a estrutura do fungo para a visualização e identificação em microscópio composto. Para compor as testemunhas foram retiradas do tratamento N0 duas amostras de 200 sementes de soja. Na primeira amostra as sementes foram tratadas com os fungicidas carboxin + thiram (TF) na dosagem de $250 \mathrm{~mL} / 100$ $\mathrm{kg}$ de sementes e na outra amostra as sementes foram submetidas à desinfestação superficial por imersão em solução de hipoclorito de sódio $2 \%$ por 5 minutos (TH). O delineamento foi inteiramente casualizado (DIC) constituídos de 5 tratamentos com 4 repetições.

Figura 1. Sementes de soja com diferentes níveis de infecção de A. ochraceus: a) N0: sementes sem inóculo visível; b) N1: sementes com até $50 \%$ de inóculo sobre a superfície; c) N2: sementes com mais de 50\% de inóculo sobre a superfície.
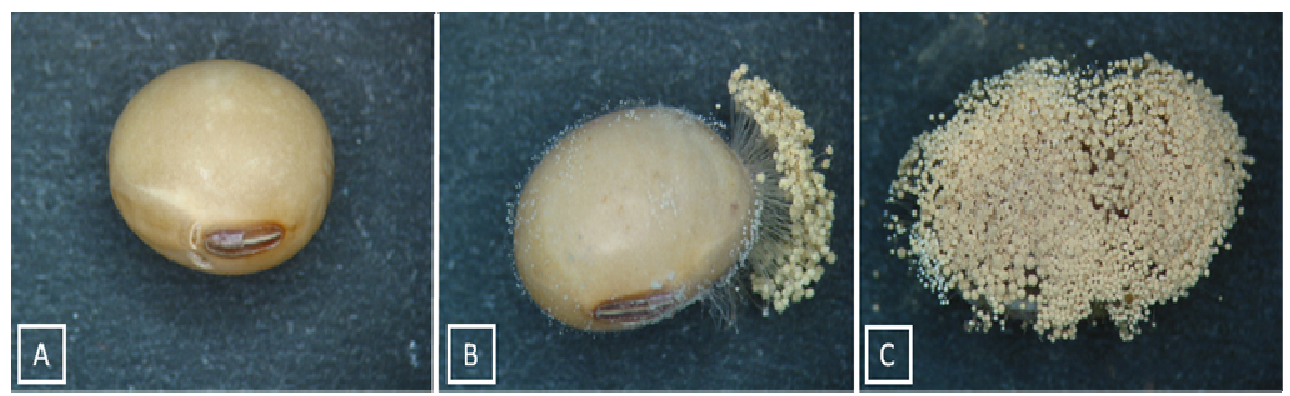

Fonte: Elaboração dos autores. 
As sementes de soja dos três níveis de infecção (N0, N1 e N2) após a restrição hídrica, foram submetidas ao teste de tetrazólio. Conforme sugerido por Costa e Marcos Filho (1994) não foi realizado o pré-condicionamento das sementes durante o teste de tetrazólio, pois foi considerado que a embebição das sementes foi satisfatória em virtude da restrição hídrica. Para tanto, 100 sementes dos respectivos tratamentos foram imersas em solução de 2, 3, 5 cloreto de trifenil tetrazólio a $0,075 \%$ e incubadas por um período de seis horas a uma temperatura de $35^{\circ} \mathrm{C}$ no escuro (BRASIL, 2009b). Em seguida, foram lavadas em água corrente, seccionadas longitudinalmente e submetidas ao exame individual em microscópio estereoscópico para avaliação da viabilidade das sementes.

$O$ teste de emergência foi realizado em bandejas de 8 litros, contendo como substrato solo e areia na proporção de 2:1. Foram semeadas 200 sementes por tratamento espaçadas $5 \times 5 \mathrm{~cm}$, em 4 repetições de 50 sementes por bandeja. As contagens iniciaramse aos cinco e estenderam-se até os 21 dias após a semeadura. A primeira contagem de emergência (PCE) corresponde à percentagem acumulada de plantas normais, registrada aos cinco dias após a semeadura. Os resultados da emergência foram expressos em porcentagem. O índice de velocidade de emergência (IVE) foi obtido por meio de contagens diárias de plântulas normais de soja dos cinco aos 21 dias após a semeadura e calculado conforme equação proposta por Maguire (1962).

Após o teste de emergência, as plântulas normais de cada repetição foram medidas para obter o comprimento das plântulas. Os dados de comprimento foram obtidos somando as médias de cada repetição por tratamento e dividido pelo número de plântulas normais, sendo os resultados expressos em centímetros (KRZYZANOWSKI; VIEIRA; FRANÇA NETO, 1999). Posteriormente, as plantas foram seccionadas e avaliou-se a massa fresca da parte aérea e da raiz, sendo pesadas 10 plântulas por repetição. Em seguida, as plântulas foram submetidas à secagem em estufa de circulação de ar forçada regulada a $65^{\circ} \mathrm{C}$, até obter massa constante.

Os dados foram submetidos à análise de variância e as médias comparadas pelo teste de Scott-Knott a $5 \%$ de probabilidade.

\section{Resultados e Discussão}

O vigor das sementes de soja cv. "Conquista" foi reduzido drasticamente com o aumento do nível de inóculo de $A$. ochraceus sobre a superfície das sementes (Tabelas 1 e 2). No nível com até $50 \%$ de inóculo (N1), observou-se a redução na primeira contagem de emergência (PCE), na emergência (E) e no índice de velocidade de emergência evidenciando que a infecção por $A$. ochraceus comprometeu o vigor das sementes de soja. Em termos de porcentagem, houve redução de $80 \%$ na emergência das plântulas, de $44 \%$ no comprimento de plântulas, de $82 \%$ na massa fresca da parte aérea e na massa fresca da raiz, de $81 \%$ na massa seca da parte aérea e $76 \%$ na massa seca da raiz quando comparados os tratamentos com até $50 \%$ de $A$. ochraceus (N1) em relação ao controle com fungicida (TF). Com níveis acima de $50 \%$ de $A$. ochraceus, as sementes apresentaram destruição de seus tecidos e perda de sua qualidade (Tabelas $1 \mathrm{e}$ 2; Figura 2).

A técnica de restrição hídrica por meio do soluto manitol a -1,0Mpa proposto por Machado et al. (2003) permitiu a detecção da infestação de A. ochraceus associada naturalmente às sementes de soja e a separação dos três diferentes níveis de infecção sobre a superfície das sementes. Apesar da infecção de $A$. ochraceus, o nível infecção N0 não diferiu dos tratamentos TF e TH, possivelmente, por que o inóculo inicial não foi suficiente para causar deterioração nas sementes. O tratamento químico (TF) com fungicida carboxin + thiram ou com hipoclorito de sódio $(\mathrm{TH})$ foram eficientes na erradicação/desinfestação de $A$. ochraceus o que contribuiu significativamente em melhor qualidade fisiológica (vigor) das sementes, expressos pelo IVE, 
PCE e emergência, em relação aos tratamentos N1 e N2 (Tabela 1). Bittencourt et al. (2007) verificaram que o tratamento de sementes de amendoim com carboxin + thiram reduziu em $63 \%$ a incidência de diversos fungos incluindo espécies de Aspergillus.
Zorato, Homechin e Henning (2001) observaram que o tratamento de sementes de soja naturalmente infectadas por A. flavus com hipoclorito de sódio a $3 \%$, com período de imersão de cinco minutos e $\mathrm{pH}$ 11,40 , proporcionou redução na incidência de $74 \%$ desse fungo nas sementes.

Tabela 1. Primeira contagem de emergência (PCE), emergência (E) e índice de velocidade de emergência (IVE) de plântulas de soja em função de diferentes níveis de infecção de Aspergillus ochraceus.

\begin{tabular}{llll}
\hline Tratamentos & PCE (\%) & E (\%) & IVE \\
\hline TH (sementes tratadas hipoclorito de sódio a 2\%) & $65,5 \mathrm{~A}$ & $80,0 \mathrm{~A}$ & $8,72 \mathrm{~A}$ \\
TF (sementes tratadas com carboxin+thiram) & $67,5 \mathrm{~A}$ & $83,0 \mathrm{~A}$ & $9,65 \mathrm{~A}$ \\
N0 (sementes visualmente sem inóculo) & $61,0 \mathrm{~A}$ & $76,0 \mathrm{~A}$ & $7,92 \mathrm{~A}$ \\
N1(sementes com até 50\% de inóculo) & $12,0 \mathrm{~B}$ & $16,5 \mathrm{~B}$ & $1,96 \mathrm{~B}$ \\
N2 (sementes com mais de 50\% de inóculo) & $00,0 \mathrm{C}$ & $00,0 \mathrm{C}$ & $0,00 \mathrm{C}$ \\
\hline \multicolumn{1}{c}{ CV(\%) } & 23,81 & 26,97 & 15,85 \\
\hline
\end{tabular}

*Médias seguidas de mesma letra na coluna não diferem estatisticamente entre si pelo teste de $\operatorname{Scott-Knott~}(\mathrm{P}<0,05)$.

Fonte: Elaboração dos autores.

Tabela 2. Comprimento de plântulas (CP), massa fresca da parte aérea (MFPA), massa fresca da raiz (MFR), massa seca da parte aérea (MSPA) e massa seca da raiz (MSR) de soja em função de diferentes níveis de infecção de Aspergillus ochraceus.

\begin{tabular}{lccccc}
\hline \multicolumn{1}{c}{ Tratamentos } & CP $(\mathrm{cm})$ & MFPA $(\mathrm{g})$ & MFR $(\mathrm{g})$ & MSPA $(\mathrm{g})$ & MSR $(\mathrm{g})$ \\
\hline TH (sementes tratadas hipoclorito de sódio a 2\%) & $21,09 \mathrm{~B}$ & $28,15 \mathrm{~A}$ & $36,57 \mathrm{~A}$ & $3,75 \mathrm{~A}$ & $1,89 \mathrm{~A}$ \\
TF (sementes tratadas com carboxin+thiram) & $25,18 \mathrm{~A}$ & $25,09 \mathrm{~A}$ & $34,53 \mathrm{~A}$ & $3,29 \mathrm{~A}$ & $1,80 \mathrm{~A}$ \\
N0 (sementes visualmente sem inóculo) & $19,95 \mathrm{~B}$ & $28,64 \mathrm{~A}$ & $43,31 \mathrm{~A}$ & $4,07 \mathrm{~A}$ & $2,34 \mathrm{~A}$ \\
N1(sementes com até 50\% de inóculo) & $14,21 \mathrm{C}$ & $4,29 \mathrm{~B}$ & $6,07 \mathrm{~B}$ & $0,61 \mathrm{~B}$ & $0,43 \mathrm{~B}$ \\
N2 (sementes com mais de 50\% de inóculo) & $0,00 \mathrm{D}$ & $0,00 \mathrm{~B}$ & $0,00 \mathrm{C}$ & $0,00 \mathrm{~B}$ & $0,00 \mathrm{~B}$ \\
\hline \multicolumn{1}{c}{ CV(\%) } & 12,38 & 21,64 & 31,27 & 21,09 & 29,75 \\
\hline
\end{tabular}

*Médias seguidas de mesma letra na coluna não diferem estatisticamente entre si pelo teste de $\operatorname{Scott-Knott~}(\mathrm{P}<0,05)$.

Fonte: Elaboração dos autores.

A emergência de plântulas pode ser diminuída devido à infecção das sementes com fungos caso não seja realizado o tratamento com fungicida (BRADLEY, 2008; MACHADO, 2000; PICININI; FERNANDES, 1996; GOULART, 2000). Por outro lado, menor incidência e infecção das sementes aumentam significativamente a eficiência dos fungicidas no desempenho fisiológico das sementes de soja (LOPES; BARROS, 1997). No presente trabalho, observou-se melhor qualidade fisiológica das sementes tratadas (TF e $\mathrm{TH}$ ) do que aquelas sementes sem inóculo visível de $A$. ochraceus e que não sofreram nenhum tipo de assepsia (N0) (Tabela 1). Verificou-se que em sementes com níveis de infecção de até $50 \%$ a emergência foi de 16,5\%, chegando não ocorrer nos níveis de infecção acima de $50 \%$ (Tabela 1 ).

No pré-teste de sanidade do lote de sementes realizado neste experimento observou-se incidência de $10,2 \%$ de $A$. ochraceus pelo método de incubação em meio ágar salino. Pereira et al. (1994) avaliaram a incidência de fungos de armazenamento em lotes de sementes de soja descartados no Estado 
de Minas Gerais na safra 1989/90, e verificaram maior frequência de espécies de Aspergillus spp. A frequência de $A$. ochraceus foi de $10,6 \%$ pelo método de incubação em meio ágar-salino e de 43,9\% pelo método de incubação em papel de filtro. Com base nestas informações, a incidência de A. ochraceus poderia ser maior do que a observada no pré-teste de sanidade realizado neste experimento, sugerindo assim, que as sementes foram contaminadas não apenas no local de armazenamento e que essa espécie fúngica apresenta grande potencial de dano em sementes de soja.

Figura 2. Caracterização de danos nas sementes de soja por meio do teste de tetrazólio conforme os níveis de infecção de A. ochraceus: a) N0: sementes sem inóculo visível; b) N1: sementes com até $50 \%$ de inóculo sobre a supefície; c) N2: sementes com mais de $50 \%$ de inóculo sobre a superfície.

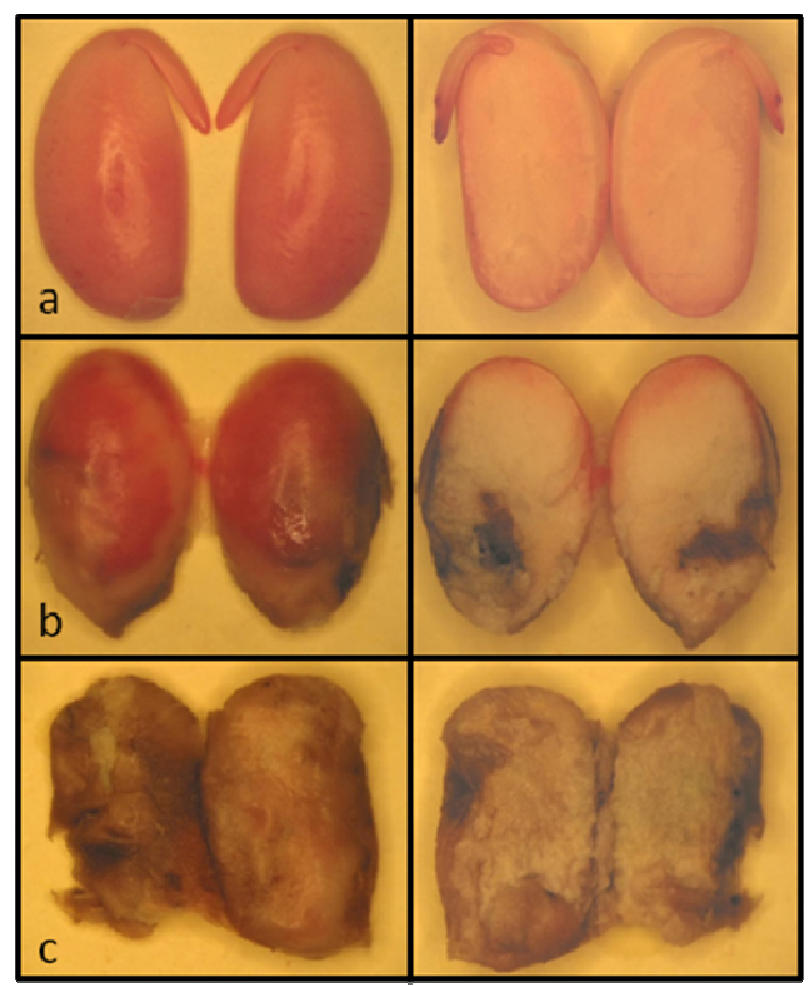

Fonte: Elaboração dos autores.

Apesar da incidência de $A$. ochraceus na semente, o tratamento com fungicida (TF), proporcionou maior comprimento de plântulas, seguidos pelos TH e N0, porém não se observou diferença significativa entre os tratamentos para as variáveis massa fresca e seca da parte aérea e raiz (Tabela 2). No entanto, redução significativa foi verificada no tratamento N1 (infecção de até $50 \%$ das sementes) para todos os parâmetros avaliados e não houve emergência no tratamento N2. O decréscimo do vigor das sementes pode afetar a produção de massa seca e a taxa de crescimento das plantas (SCHUCH et al., 2000;
KOLCHINSKI; SCHUCH; PESKE, 2005). Desse modo a redução do vigor das sementes em N1 e N2, verificada nos testes de emergência e índice de velocidade de emergência, refletiu em menor ou nenhum crescimento das plântulas. $\mathrm{O}$ efeito do parasitismo de $A$. ochraceus sobre as sementes de soja nos tratamentos N1 e N2 foram claramente demonstrados após caracterização dos danos causados as sementes pelo teste de tetrazólio (Figura 2). Os patógenos causam danos às sementes através da interferência em diversos processos fisiológicos essenciais, destruindo órgãos de reserva ou tecidos 
jovens; danificando o sistema radicular ou o sistema vascular de plântulas, afetando, respectivamente, a absorção e o transporte de água e nutrientes. Esses danos ocorrem pela ação de enzimas, toxinas e reguladores de crescimento produzidos por esses microrganismos. A infecção por A. ochraceus pode ter promovido alterações nos padrões eletroforéticos de certas enzimas, o que pode ter contribuído para acelerar o processo de deterioração da semente. Silva et al. (2000) constataram que a infecção de sementes de milho com $A$. flavus promoveu alterações dos padrões isoenzimáticos, tanto na intensidade como no número de bandas das enzimas álcooldesidrogenase e malato-desidrogenase. Portanto, a ação bioquímica de microrganismos está relacionada com a ação de enzimas envolvidas na degradação da parede celular do tecido vegetal e na produção de toxinas as quais irão causar decomposição dos tecidos vivos, causando assim aumento da taxa respiratória do hospedeiro e por consequência a deterioração da semente (HENNING et al., 2009).

\section{Conclusões}

Aspergillus ochraceus reduz drasticamente o vigor das sementes de soja, causando drestruição total dos tecidos em níveis acima de $50 \%$ do inóculo sobre a superfície das sementes. Já em níveis de infecção inferiores a $50 \%$ proporciona menor desempenho fisiológico das sementes. O método de restrição hídrica favorece o desenvolvimento de diferentes níveis de $A$. ochraceus e impede a germinação das sementes de soja.

\section{Referências}

ALMEIDA, A. P. M. M.; DIAS, E. S.; PEREIRA, R. T. G.; TOLEDO, R. C. C.; PFENNING, L. H. Obtenção de protoplastos do fungo filamentoso Aspergillus ochraceus. Ciência Rural, Santa Maria, v. 38, n. 5, p. 1460-1462, 2008.

ARAUJO, D. V.; POZZA, E. A.; MACHADO, J. C.; ZAMBENEDETTI, E. B.; CELANO, F. A. O.; CARVALHO, E. M.; CAMARGO, V. N. Influência da temperatura e do tempo de inoculação das sementes de algodão na transmissibilidade de Colletotrichum gossypii var. cephalosporioides. Fitopatologia Brasileira, Brasília, v. 31, n. 1, p. 35-40, 2006.

BATISTA, L. R.; CHAULFON, S. M.; PRADO, G.; SCHWAN, R. F.; WHEALS, A. E. Toxigenic fungi associated with processed (green) coffee beans (Coffea arabica L.). International Journal of Food Microbiology, Torino, v. 85, n. 3, p. 293-300, 2003.

BITTENCOURT, S. R. M.; MENTEN, J. O. M.; ARAKI, C. A. S.; MORAES, M. H. D.; RUGAI, A. D.; DIEGUEZ, M. J.; VIEIRA, R. D. Eficiência do fungicida carboxin + thiram no tratamento de sementes de amendoim. Revista Brasileira de Sementes, Londrina, v. 29, n. 2, p. 214-222, 2007.

BRACCINI, A. L.; MOTTA, I. S.; SCAPIM, C. A.; BRACCINI, M. C. L.; ÁVILA, M. R.; SCHUAB, S. R. P. Semeadura da soja no período de safrinha: potencial fisiológico e sanidade das sementes. Revista Brasileira de Sementes, Pelotas, v. 25, n. 1, p. 76-86, 2003.

BRADLEY, C. A. Effect of fungicide seed treatments on stand establishment, seedling disease, and yield of soybean in North Dakota. Plant Disease, St. Paul, v. 92, n. 1, p. 120-125, 2008.

BRASIL. Ministério da Agricultura e Reforma Agrária. Regras para análises de sementes. Brasília, DF: SNDA/ DNDV/CLAV, 2009b. 398 p.

BRASIL. Ministério da Agricultura, Pecuária e Abastecimento. Manual de análise sanitária de sementes. Brasília, DF, 2009a. 202 p.

CARVALHO, N. M.; NAKAGAWA, J. Sementes: ciência, tecnologia e produção. Jaboticabal: FUNEP, 2000. $588 \mathrm{p}$.

CATÃO, H. C. R. M.; COSTA, F. M.; VALADARES, S. V.; DOURADO, E. R.; BRANDÃO JUNIOR, D. S.; SALES, N. L. P. Qualidade física, fisiológica e sanitária de semente de milho crioulo produzidas no norte de Minas Gerais. Ciência Rural, Santa Maria, v. 40, n. 10, p. 2060-2066, 2010.

CATÃO, H. C. R. M.; MAGALHÃES, H. M.; SALES, N. L. P.; BRANDÃO JUNIOR, D. S.; ROCHA, F. S. Incidência e viabilidade de sementes crioulas de milho naturalmente infestadas com fungos em pré e pósarmazenamento. Ciência Rural, Santa Maria, v. 43, n. 5, p. 764-770, 2013.

COSTA, N. P.; MARCOS FILHO, J. Temperatura e précondicionamento de sementes de soja para o teste de tetrazólio. Scientia Agricola, Piracicaba, v. 51, n. 1, p. 158-168, 1994. 
COUTINHO, W. M.; MACHADO, J. C.; VIEIRA, M. G. G. C.; GUIMARÃES, R. M.; FERREIRA, D. F. Uso da restrição hídrica na inibição ou retardamento da germinação de sementes de arroz e feijão submetidas ao teste de sanidade em meio agar-água. Revista Brasileira de Sementes, Londrina, v. 23, n. 2, p. 127-135, 2001.

CHRISTENSEN, M. The Aspergillus ochraceus group: two new species from western soils and a synoptic key. Mycologia, New York, v. 74, n. 2, p. 210-225, 1982.

FARIAS, C. R. J.; DEL PONTE, E. M.; CORRÊA, C. L.; AFONSO, A. P.; PIEROBOM, C. R. Infecção de sementes de trigo com Bipolares sorokiniana pela técnica de restrição hídrica. Tropical Plant Pathology, Brasília, v. 35 , n. 4, p. 253-257, 2010.

GALLI, J. A.; PANIZZI, R. C.; VIEIRA, R. D. Efeito de Colletotrichum dematium var. truncata e Phomopsis sojae na qualidade sanitária e fisiológica nas sementes de soja. Summa Phytopathologica, Botucatu, v. 33, n. 1, p. 40-46, 2007.

GOULART, A. C. P. Eficiência de diferentes fungicidas no controle de patógenos em sementes de soja e seus efeitos na emergência e no rendimento de grãos da cultura. Informativo ABRATES, Londrina, v. 10, n. 1/2/3, p. 17-24, 2000.

HENNING, F. A.; MERTZ, L. M.; ZIMMER, P. D.; TEPLIZKY, M. D. F. Qualidade fisiológica, sanitária e análise de izoenzimas de sementes de aveia preta tratadas com diferentes fungicidas. Revista Brasileira de Sementes, Londrina, v. 31, n. 9, p. 63-69, 2009.

KLICH, M. A.; PITT, J. I. A laboratory guide to the common Aspergillus species and their teleomorphs. Austrália: CSIRO - Division of Food Processing, 2002. $116 \mathrm{p}$.

KOLCHINSKI, E. M.; SCHUCH, L. O. B.; PESKE, S. T. Vigor de sementes e competição intraespecífica em soja. Ciência Rural, Santa Maria, v. 35, n. 6, p. 1248-1256, 2005.

KROHN, N. G.; MALAVASI, M. M. Qualidade fisiológica de sementes de soja tratadas com fungicidas durante e após o armazenamento. Revista Brasileira de Sementes, Pelotas, v. 26, n. 2, p. 91-97, 2004.

KRZYZANOWSKI, F. C.; VIEIRA, R. D.; FRANÇA NETO, J. B. Vigor de sementes: conceitos e testes. Londrina: Informativo ABRATES, 1999. 218 p.

LOPES, M. E. B. M.; BARROS, B. C. Eficiência de fungicidas no controle de fungos em sementes de soja (Glycine $\max$ (L.) Merrill). Revista de Agricultura, Piracicaba, v. 72, n. 1, p. 85-98, 1997.
LUZ, W. C. Diagnose e controle das doenças da espiga de milho no Brasil. Passo Fundo: EMBRAPA, CNPT, 1995. 28 p. (Circular técnica, 5).

MACHADO, J. C. Tratamento de sementes no controle de doenças. Lavras: LAPS/UFLA/FAEPE, 2000. 138 p.

MACHADO, J. C.; COUTINHO, W. M.; GUIMARÃES, R. M.; VIEIRA, M. G. G.C.; FERREIRA, D. F. Use of osmotic solutes to control seed germination of rice and common bean in seed health blotter tests. Seed Science and Technology, Zürich, v. 36, n. 1, p. 66-75, 2008.

MACHADO, J. C.; LANGERAK, C. J. General incubation methods for routine seed health analysis. In: MACHADO, J. C.; LANGERAK, C. J.; JACCOUDFILHO, D. S. (Ed.). Seed-borne fungi: a contribution to routine seed health analysis. International Seed Testing Association. Bassersdorf, 2002. p. 48-80.

MACHADO, J. C.; OLIVEIRA, J. A.; VIEIRA, M. G. G. C.; ALVES, M. C. Controle da germinação de sementes de soja em testes de sanidade pelo uso da restrição hídrica. Revista Brasileira de Sementes, Pelotas, v. 25, n. 2, p. 77-81, 2003.

. Uso da restrição hídrica na inoculação de fungos em sementes de algodoeiro (Gossypium hirsutum). Revista Brasileira de Sementes, Pelotas, v. 26, n. 1, p. 62-67, 2004.

MAGUIRE, J. D. Speed of germination-aid in selection and evaluation for seedling emergence and vigor. Crop Science, Madison, v. 2, n. 1, p. 176-177, 1962.

MICHEL, B. E.; RADCLIFFE, D. A computer program relating solute potential to solution composition for five solutes. Agronomy Journal, Madison, v. 87, n. 1, p. 126130, 1995.

MILLER, J. D. Fungi and mycotoxins in grain: implications for stored product research. Journal Stored Products Research, Great Britain, v. 31, n. 1, p. 1-16, 1995.

PEREIRA, G. F. A.; MACHADO, J. C.; SILVA, R. L. X.; OLIVEIRA, S. M. A. Fungos de armazenamento em lotes de sementes de soja descartados no Estado de Minas Gerais na safra 1989/90. Revista Brasileira de Sementes, Brasília, v. 16, n. 2, p. 216-219, 1994.

PICININI, E. C.; FERNANDES, J. M. C. Eficácia de fungicidas no controle de patógenos em sementes de soja. Fitopatologia Brasileira, Brasília, v. 21, n. 4, p. 492-495, 1996.

PINTO, N. F. J. A. Patologia de sementes de milho. Sete Lagoas: EMBRAPA, CNPMS, 1998. 44 p. (Circular Técnica, 29). 
RAPER, K. B.; FENNEL, D. I. The genus Aspergillus. Baltimore: The Williams and Wilkins Company, 1965. $686 \mathrm{p}$.

SCHUCH, L. O. B.; NEDEL, J. L.; ASSIS, F. N.; MAIA, M. S. Vigor de sementes e análise de aveia preta. Scientia Agricola, Piracicaba, v. 57, n. 2, p. 305-312, 2000.

SILVA, E. A. M.; VON PINHO, E. V. R.; VIEIRA, M. G. G. C.; CARVALHO, M. L. M.; MACHADO, J. C. Alterações dos padrões de izoenzimas em sementes de milho infectadas por fungos. Pesquisa Agropecuária Brasileira, Brasília, v. 35, n. 9, p. 1725-1732, 2000.

SUÁREZ-QUIROZ, M. L.; GONZÁLEZ-RIOS, O.; BAREL, M.; GUYOT, B.; SCHORR-GALINDO, S.; GUIRAUD, J. P. Effect of chemical and environmental factors on Aspergillus ochraceus growth and toxigenesis in green coffee. Food Microbiology, London, v. 21, n. 6, p. 629-634, 2004.
TANAKA, M. A. S. Sobrevivência de Fusarium moniliforme em sementes de milho mantidas em duas condições de armazenamento. Fitopatologia Brasileira, Brasília, v. 26, n. 1, p. 60-64, 2001.

TUITE, J.; KOH-KNOX, C; STROSHINE, R.; CANTONE, F. A.; BAUMAN, L. F. Effect of physical damage to corn kernels on the development of Penicillium species and Aspergillus glaucus in storage. Phytopathology, West Lafayette, v. 75, n. 10, p. 11371140, 1985.

ZORATO, M. F.; HOMECHIN, M.; HENNING, A. A. Efeitos da assepsia superficial com diferentes agentes químicos na incidência de microrganismos em sementes de soja. Revista Brasileira de Sementes, Brasília, v. 23, n. 1, p. 159-166, 2001. 
